\title{
Local Opioid Withdrawal in Rat Single Periaqueductal Gray Neurons In Vitro
}

\author{
Billy Chieng and MacDonald J. Christie \\ Department of Pharmacology, The University of Sydney, NSW 2006, Australia
}

Opioid dependence in ventrolateral periaqueductal gray (PAG) neurons was studied by using intracellular recordings from brain slices. In slices from morphine-dependent rats maintained in morphine $(5 \mu \mathrm{M})$ in vitro, action potential frequencies of opioid-sensitive neurons did not differ from untreated control neurons but were greater than in control neurons maintained in morphine in vitro, indicating development of tolerance. Naloxone $(100 \mathrm{~nm}$ or $1 \mu \mathrm{M})$ depolarized 25 of 51 neurons from morphine-dependent rats maintained in morphine in vitro, 19 of which previously had been classified as opioid-sensitive. Action potential frequencies in the presence of naloxone were greater than in control neurons in the absence of opioids, as well as in control neurons in the presence of both morphine and naloxone, demonstrating opioid withdrawal. In slices from control animals, opioid-induced hyperpolarizations and naloxoneinduced depolarizations (in the presence of morphine) reversed polarity near expected $E_{\mathrm{K}}(-111 \pm 3 \mathrm{mV}$ and $-113 \pm 3 \mathrm{mV}$, respectively). In contrast, the reversal potential of naloxoneinduced depolarizations was more negative than expected in neurons from dependent animals $(-143 \pm 9 \mathrm{mV})$, indicating that the depolarization was not attributable simply to antagonism of a K-conductance increase. Naloxone-induced depolarizations were not inhibited by tetrodotoxin $(1 \mu \mathrm{M})$, bicuculline (30 $\mu \mathrm{M}), 6-c y a n o-7-n i t r o q u i n o x a l i n e-2,3-d i o n e ~(10 \mu \mathrm{M})$, or prazosin (300 nM), suggesting no involvement of major synaptic neurotransmitters. Clonidine $(1 \mu \mathrm{M})$ and baclofen $(30 \mu \mathrm{M})$ overcame naloxone-induced depolarizations. These results demonstrate development of both tolerance and withdrawal in PAG neurons and suggest induction of a novel opioid-sensitive current that could be involved in withdrawal behavior.

Key words: periaqueductal gray; opiate withdrawal; drug dependence; morphine; naloxone; clonidine; brain slices
Opioid tolerance and dependence result from adaptations that develop in multiple neural systems after chronic exposure to opioids. Tolerance, or a diminished responsiveness to the inhibitory actions of opioids, has been widely demonstrated to occur in opioid-sensitive cells. The adaptive mechanisms underlying tolerance generally are thought to involve functional uncoupling between opioid receptors and their effectors (Law et al., 1982; Chavkin and Goldstein, 1984; Christie et al., 1987; Puttfarcken et al., 1988). However, opioid receptor-effector uncoupling cannot account fully for physical dependence, which is characterized by withdrawal signs, or abnormal rebound responses in single neurons after administration of an opiate antagonist.

Biochemical indices of withdrawal rebound, such as hypertrophy of adenylyl cyclase activity, have been widely reported to occur in isolated cells during opioid withdrawal (Sharma et al., 1975; Nestler et al., 1993). However, clear evidence of withdrawal in the membrane properties of single neurons has remained elusive, despite the demonstration of tolerance in the same preparations (Andrade et al., 1983; Christie et al., 1987; Wimpey et al., 1989; Kennedy and Henderson, 1991, 1992). For example, although there is a profound increase in action potential activity of locus coeruleus neurons during systemically induced withdrawal in

\footnotetext{
Received June 13, 1996; revised Aug. 26, 1996; accepted Aug. 30, 1996.

This work was supported by the National Health and Medical Research Council of Australia. We gratefully acknowledge donation of morphine pellets, (+)-naloxone, and DAMGO by the National Institute on Drug Abuse. We thank Drs. M. Connor and C. W. Vaughan for their helpful comments.

Correspondence should be addressed to Dr. MacDonald J. Christie, Department of Pharmacology D06, The University of Sydney, NSW 2006, Australia.

Dr. Chieng's present address: The Vollum Institute, Oregon Health Sciences University, Portland, OR 97201.

Copyright (C) 1996 Society for Neuroscience $0270-6474 / 96 / 167128-09 \$ 05.00 / 0$
}

vivo, this has been suggested to be attributable almost completely to enhanced excitatory afferent drive (Tung et al., 1990; Akaoka and Aston-Jones, 1991). In vitro functional uncoupling of the opioid-induced K-conductance increase was demonstrated clearly in the locus coeruleus (Andrade et al., 1983; Christie et al., 1987), but a small $(0.6 \mathrm{~Hz}$, Kogan et al., 1992) excitation, representing only a fraction of withdrawal in vivo, or no withdrawal rebound (Andrade et al., 1983; Christie et al., 1987) was observed. Enhanced excitability of CNS neurons also has been reported to occur during opioid withdrawal in cerebral cortex (Fry et al., 1980), hypothalamus (Russell et al., 1995), and dorsal horn of the spinal cord (Johnson and Duggan, 1981), but neither membrane mechanisms nor the role of synaptic transmission has been identified clearly.

A possible explanation for the failure to demonstrate clear evidence of withdrawal in isolated cells is that the adaptive processes underlying dependence develop only in subpopulations of opioid-sensitive neurons or are distributed among networks of neurons that are involved in expression of characteristic signs of opioid withdrawal in vivo. A number of brain regions have been implicated from microinjection studies to be involved in the expression of withdrawal behavior in vivo. Functional and biochemical studies have suggested a role for the periaqueductal gray (PAG) in the expression of many withdrawal signs (Bozarth and Wise, 1984; Kimes and London, 1989; Maldonado et al., 1992; Stornetta et al., 1993; Bozarth, 1994; Chieng et al., 1995; Couceyro and Douglass, 1995). Numbers of neurons expressing c-fos immunoreactivity after opioid withdrawal in both awake and anesthetized rats were elevated in lateral and ventrolateral subdivisions of the PAG, predominantly in the caudal areas of ventrolateral PAG (Chieng et al., 1995). However, no electrophysiological studies 
have examined dependence in single PAG neurons. The present study examined withdrawal behavior of single ventrolateral PAG neurons by intracellular recordings from brain slices. A preliminary account of these findings has been presented elsewhere (Chieng and Christie, 1995a).

\section{MATERIALS AND METHODS}

Chronic treatment with morphine. Male Sprague Dawley rats (150-250 gm) were implanted subcutaneously with pellets containing $75 \mathrm{mg}$ of morphine base or received sham surgery under halothane anesthesia. This procedure was performed on alternate days for $5 \mathrm{~d}(1,2$, and then 2 pellets). Alternatively, rats were injected subcutaneously with a morphine suspension $(55 \mathrm{mg} / \mathrm{kg}$ morphine base, $0.2 \mathrm{ml} / \mathrm{kg}$ Arlacel A emulsifier, and $0.8 \mathrm{ml} / \mathrm{kg}$ light liquid paraffin made up to $2 \mathrm{ml} / \mathrm{kg}$ with $0.9 \% \mathrm{NaCl}$ in water; see Collier et al., 1972), and the procedure was repeated on alternate days for $5 \mathrm{~d}$. Opiate-dependent rats were used for electrophysiological experiments $2 \mathrm{~d}$ after the final implantation or injection. Both procedures induced a similar intensity of naloxone-precipitated withdrawal signs in separate experiments (Chieng and Christie, 1995b; C. E. Bellchambers, B. Chieng, K. A. Keay, and M. J. Christie, unpublished observations).

Preparation of tissue and solutions. Rats were anesthetized with halothane and decapitated; horizontal brain slices containing PAG $(300 \mu \mathrm{m})$ were cut and maintained in physiological saline at $35^{\circ} \mathrm{C}$, as described previously (Chieng and Christie, 1994a). Slices containing PAG ventral to the aqueduct were transferred to a tissue bath and superfused submerged with physiological saline at $35^{\circ} \mathrm{C}(1.5 \mathrm{ml} / \mathrm{min})$. The physiological saline solution contained (in mM): $126 \mathrm{NaCl}, 2.5 \mathrm{KCl}, 1.2 \mathrm{NaH}_{2} \mathrm{PO}_{4}, 1.2 \mathrm{MgCl}_{2}$, $2.4 \mathrm{CaCl}_{2}, 11$ glucose, and $24 \mathrm{NaHCO}_{3}$ and was gassed with $95 \% \mathrm{O}_{2} / 5 \%$ $\mathrm{CO}_{2}$. Drugs were applied to the slice by changing the solution to one that differed only in its content of the drug.

Experimental groups. Membrane properties of neurons from three experimental groups were examined. For the dependent group, animals were treated chronically with morphine, and slices were maintained in vitro in morphine $(5 \mu \mathrm{M})$ to mimic brain concentrations of morphine reported previously with similar treatment procedures (Christie et al., 1987). For the untreated group, animals were either untreated or subjected to sham treatment procedures (injections or implantation surgery). The in vitro morphine group was used to control for the sustained presence of morphine in tissue from the dependent group and for short-term adaptations that might result (Osborne and Williams, 1995; Fiorillo and Williams, 1996). For the in vitro morphine group, brain slices were prepared from untreated animals and maintained in morphine (5 $\mu \mathrm{M}$ ) for the duration of experiments (from 1 to $10 \mathrm{hr}$ ).

Electrophysiological recording. Intracellular recordings of membrane potential and current were made with microelectrodes $(60-120 \mathrm{M} \Omega$, filled with $2 \mathrm{M} \mathrm{KCl}$ plus $2 \%$ biocytin buffered with $50 \mathrm{~mm}$ Tris $\mathrm{HCl}, \mathrm{pH}$ 7.4; Axoclamp-2A amplifier) as described previously (Chieng and Christie, 1994a). The approximate locations of impaled neurons were plotted by an atlas of the rat brain (Paxinos and Watson, 1986) and later confirmed after staining of biocytin, as described previously (Chieng and Christie, 1994a). Recordings of membrane potential and applied current were plotted directly on chart recorder paper and also digitized for later analyses (PCLAMP and AXOTAPE software, Axon Instruments, Foster City, CA). Electrode resistance was monitored and balanced throughout experiments. Only cells that had action potential amplitude of at least 50 $\mathrm{mV}$, duration of $<1.5 \mathrm{msec}$, threshold of at least $-50 \mathrm{mV}$ (although amplitudes were usually $65-75 \mathrm{mV}$ ), and input resistance of at least 50 $\mathrm{M} \Omega$ were used for data analysis. For measurement of the amplitude of hyperpolarizations, membrane potential was held between -65 and -75 $\mathrm{mV}$ by application of constant current through the recording electrode. Input resistance was determined throughout with brief $(250 \mathrm{msec})$ hyperpolarizing current pulses $(0.2$ to $0.3 \mathrm{~Hz},-40$ to $-200 \mathrm{pA})$. For determination of current-voltage relationships, membrane potential was monitored over a range (usually -50 to $-150 \mathrm{mV}$ ) by applying an incremental series of current pulses of $200 \mathrm{msec}$ duration. In these cases, the basal membrane potential was adjusted to control values during drug application by application of constant current. The total applied current was used to determine current-voltage relationships. In several cases stable recordings were achieved with sufficiently low resistance electrodes $(60-80 \mathrm{M} \Omega)$ to permit the use of discontinuous voltage clamp at switching frequencies of $2-3 \mathrm{kHz}$ while continuously monitoring the potential at the headstage with a separate oscilloscope. All data are expressed as mean \pm SEM.
Drugs and reagents. Arlacel A, baclofen, biocytin, clonidine, ExtrAvidin peroxidase, met-enkephalin, and tetrodotoxin were obtained from Sigma (St Louis, MO), ( \pm )-2-amino-5-phosphonovaleric acid (APV), (-)bicuculline methiodide, 6-cyano-7-nitroquinoxaline-2,3-dione (CNQX), naloxone hydrochloride from Research Biochemicals (Natick, MA), and morphine hydrochloride and morphine base from Glaxo (United Kingdom). Morphine base pellets, (+)-naloxone, and Tyr-D-Ala-Gly-MePheGlyol (DAMGO) were generously donated by the National Institute on Drug Abuse (NIDA; Bethesda, MD). Idazoxan hydrochloride was obtained from Reckitt and Colman (United Kingdom). Prazosin hydrochloride was from Pfizer (United Kingdom).

\section{RESULTS}

\section{Postsynaptic opioid sensitivity of PAG neurons}

We reported previously that $\sim 30 \%$ of neurons in lateral and ventrolateral PAG were hyperpolarized directly by $\mu$-opioids (Chieng and Christie, 1994a). In the present study we considered that adaptations resulting from chronic treatment with morphine might occur in neurons directly affected by opioids, so we characterized them as opioid-sensitive or opioid-insensitive on the basis of their response to a high concentration of met-enkephalin. Met-enkephalin $(30 \mu \mathrm{M})$ produced a small hyperpolarization or outward current in $40 \%(n=26 / 65)$ of neurons in slices from dependent animals in the presence of morphine $(-5 \pm 1 \mathrm{mV}, n=$ $23 ; 20 \pm 8 \mathrm{pA}$ at a holding potential of $-60 \mathrm{mV}, n=3$, for voltage clamp; Fig. $2 A$ ). Met-enkephalin hyperpolarizations were scored as a positive if they were $>1 \mathrm{mV}$ and displayed a "typical" time course of graded onset and washout over several minutes. Although this method might have produced some false negative results, we considered the observations to provide a reasonable classification of sensitivity to opioids in dependent slices, because the proportion of neurons hyperpolarized was similar to that found in slices from untreated animals, i.e., $33 \%\left(n=48 / 147 ; \chi^{2}\right.$ $=2.2 ; p>0.1$; see also Chieng and Christie, 1994a). A hyperpolarization was also produced in $39 \%(n=7 / 18)$ of neurons in the in vitro morphine group $(-5 \pm 1 \mathrm{mV} ; n=7)$.

\section{PAG neurons were tolerant to morphine after chronic treatment}

Spontaneous action potential frequencies of opioid-sensitive neurons in untreated and dependent groups were similar despite the sustained presence of morphine $(5 \mu \mathrm{M})$ in the dependent group (Fig. $1 A ; p>0.5$; Wilcoxon rank sum test). In contrast to untreated slices, no opioid-sensitive neurons in the in vitro morphine group $(n=7)$ were spontaneously active in the presence of $5 \mu \mathrm{M}$ morphine $\left(\chi^{2}=5.0 ; p<0.05\right)$. These results demonstrate that tolerance had developed to the sustained presence of morphine after chronic morphine treatment. Input resistances of opioid-sensitive neurons did not differ significantly between slices from naive animals in the absence of opioids (243 \pm $29 \mathrm{M} \Omega ; n=26$ ), untreated slices in the presence of $5 \mu \mathrm{M}$ morphine $(168 \pm 27 \mathrm{M} \Omega ; n=7)$, nor dependent slices in the presence of $5 \mu \mathrm{M}$ morphine $(191 \pm 22 \mathrm{M} \Omega ; n=26)$. Consistent with tolerance, there was a trend for the input resistance of opioid-sensitive neurons from untreated slices in the presence of morphine to be less than untreated slices in the absence of morphine and for dependent slices in the presence of morphine to be intermediate. However, these differences did not reach statistical significance, presumably because the opioid-induced change in input resistance was obscured during comparisons between groups by the basal variability of input resistance, i.e., opioids would be expected to produce a $17 \%$ decrease in input resistance in untreated slices (Chieng and Christie, 1994a) from 243 to 201 $\mathrm{M} \Omega$, which is well within the $95 \%$ confidence interval for input 

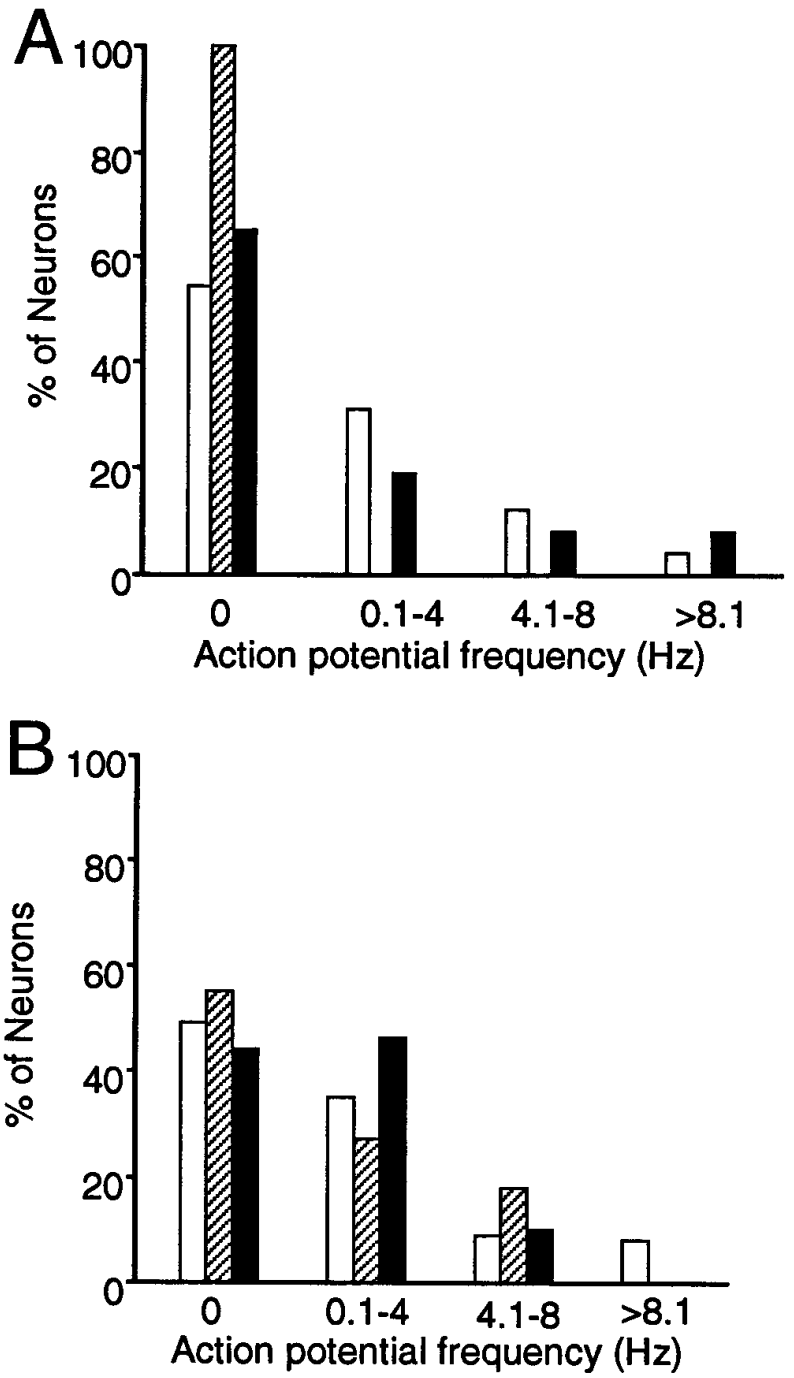

Figure 1. Spontaneous action potential frequencies of PAG neurons after chronic treatment with morphine. Neurons in each group were classified as opioid-sensitive $(A)$ or opioid-insensitive $(B)$ on the basis of whether or not they were hyperpolarized by met-enkephalin $(30 \mu \mathrm{M})$. Spontaneous action potential frequencies in the absence of applied currents were sampled in control neurons in the absence of opioids (open bars), control neurons in the presence of morphine ( $5 \mu \mathrm{M}$ for up to $10 \mathrm{hr}$; hatched bars), or neurons from dependent animals in the presence of morphine (filled bars). Opioid-sensitive neurons $(A)$ from dependent animals $(n=26)$ had similar action potential frequencies to untreated control neurons in the absence $(n=26)$, but not the presence $(n=7)$, of morphine, demonstrating development of tolerance (see Results for statistical analyses). Action potential frequencies of opioid-insensitive neurons from dependent $(n=39)$ and control slices in the absence $(n=80)$ or presence $(n=11)$ of morphine were similar.

resistance (300-186 M $\Omega$ ). Other membrane properties, including action potential amplitude, duration, and afterhyperpolarization of opioid-sensitive neurons, were also similar to those reported previously by Chieng and Christie (1994a) and did not differ between treatment groups (data not shown).

Membrane properties of "opioid-insensitive" neurons, including input resistance (untreated: $282 \pm 19 \mathrm{M} \Omega, n=80$; in vitro morphine: $243 \pm 29 \mathrm{M} \Omega, n=11$; dependent: $255 \pm 18 \mathrm{M} \Omega, n=$ 37), action potential amplitude, duration, afterhyperpolarization, and spontaneous action potential frequency (Fig. $1 B$ ), were also similar to those reported previously by Chieng and Christie
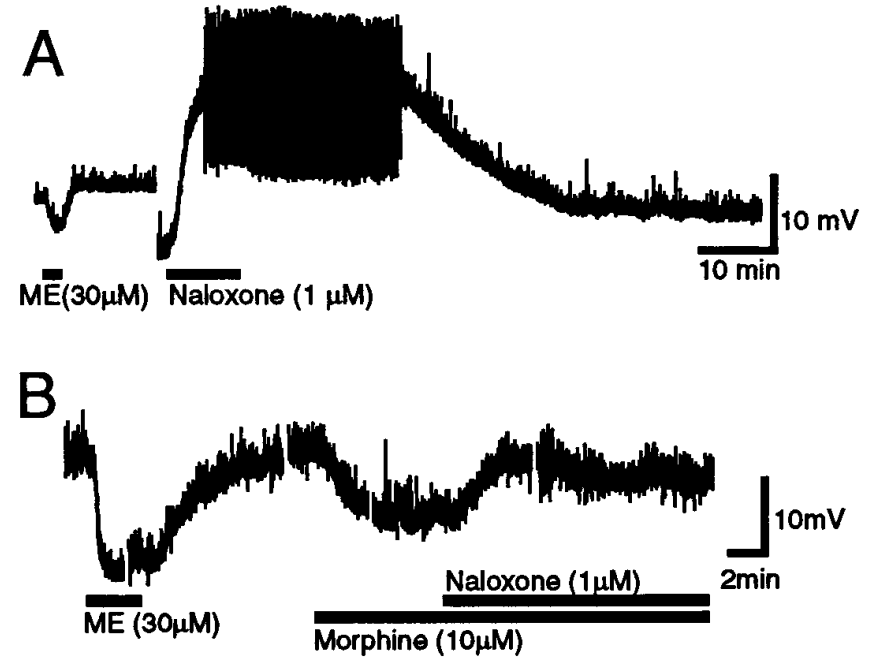

Figure 2. Naloxone $(1 \mu \mathrm{M})$ depolarized an opioid-sensitive neuron maintained in morphine $(5 \mu \mathrm{M})$ in vitro from a dependent animal. $A$, Metenkephalin $(M E, 30 \mu \mathrm{M}$, indicated by bar under trace) hyperpolarized the neuron (from $-71 \mathrm{mV},-30 \mathrm{pA}$ applied current; resting membrane potential was $-66 \mathrm{mV}$ ). Then the neuron was hyperpolarized to $-85 \mathrm{mV}$ by applying a $-100 \mathrm{pA}$ constant current to illustrate the possible amplitude of naloxone-induced depolarizations without the confounding influence of action potential activity. Naloxone superfusion then depolarized the neuron beyond threshold $(22 \mathrm{mV}$; breaks in traces of $\sim 2$ min each for determination of voltage-current relationships) (data not shown). $B$, Responses of a control neuron to met-enkephalin $(M E, 30 \mu \mathrm{M})$, morphine $(10 \mu \mathrm{M})$, and morphine plus naloxone $(1 \mu \mathrm{M})$ for comparison (from -70 $\mathrm{mV},-30 \mathrm{pA}$ applied current; neuron was spontaneously active in the absence of applied current). Voltage-current relationships were determined during breaks in traces (actual breaks were $\sim 2$ min each).

(1994a) and did not differ between treatment groups. These results suggest that the general membrane properties of neurons were similar among the three groups and that adaptive changes observed after chronic morphine were not an artifact arising from treatment-induced differences in the quality of tissue preparations.

\section{Naloxone-induced withdrawal depolarization demonstrates dependence in single opioid-sensitive PAG neurons}

Naloxone (0.1-1.0 $\mu \mathrm{M})$ produced a depolarization, or an inward current with voltage clamp, in $49 \%(25 / 51)$ of opioid-sensitive and opioid-insensitive neurons from dependent slices, often producing firing of action potentials (Fig. $2 A$ ). For comparison, Figure $2 B$ shows the effects of met-enkephalin, morphine, and naloxone in a PAG neuron from an untreated animal. Naloxone-induced depolarizations occurred predominantly in opioid-sensitive neurons (Fig. 3; $n=19 / 25$ ); only 6 of 31 neurons categorized as opioidinsensitive were depolarized by naloxone, and one categorized as opioid-sensitive was unaffected $\left(n=1 / 26 ; \chi^{2}=27.9 ; p<0.001\right)$. It is not clear whether the six neurons classified as opioidinsensitive did indeed express opioid receptors but were sufficiently tolerant to opioids that we failed to detect a metenkephalin-induced hyperpolarization in the presence of $5 \mu \mathrm{M}$ morphine.

Naloxone produced a depolarization of $9 \pm 2 \mathrm{mV}(n=18$; Fig. $2 A$ ) in opioid-sensitive neurons from dependent animals when membrane potential was maintained with constant current between -80 and $-87 \mathrm{mV}$. This value underestimates the actual amplitude of the naloxone-induced depolarization because mem- 


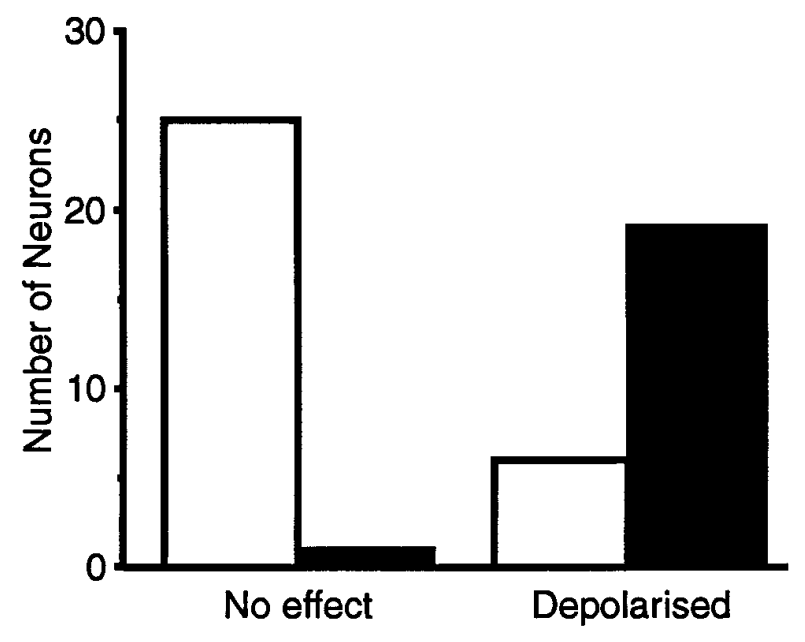

Figure 3. Numbers of opioid-sensitive (filled bars) and opioid-insensitive (open bars) neurons from morphine-dependent animals that were unaffected (left) or depolarized by naloxone (right).

brane potential reached threshold during superfusion of naloxone in several cases (Fig. 2A). When single electrode voltage clamp was possible, naloxone produced an inward current $(80 \pm 6 \mathrm{pA}$, holding at $-65 \mathrm{mV} ; n=3)$. Depolarizations were sustained without decline throughout superfusions with naloxone (tested for up to $75 \mathrm{~min}$ ) and reversed after a period of washout (Fig. 2A). Naloxone-induced depolarizations were mediated by occupation of opioid receptors. The inactive enantiomer $(+)$-naloxone $(1 \mu \mathrm{M})$ failed to produce any depolarization in neurons that subsequently were depolarized by $(-)$-naloxone $(n=2)$. Furthermore, depolarizations induced by naloxone could be surmounted by additional superfusion of high concentrations of the $\mu$-receptor agonist DAMGO (30 $\mu \mathrm{M} ; n=3)$.

Figure 4 shows spontaneous action potential frequency of opioid-sensitive neurons from dependent and in vitro morphinetreated slices in the presence of naloxone and untreated slices in the absence of naloxone. In the presence of naloxone, the proportion of opioid-sensitive neurons displaying spontaneous action potential activity was greater in slices from dependent animals than in untreated slices $\left(\chi^{2}=10.2 ; p<0.005\right)$. The median action potential frequency of opioid-sensitive neurons from dependent animals $(1.5 \mathrm{~Hz})$ was also greater than that of neurons from untreated slices $\left(0 \mathrm{~Hz}\right.$; Wilcoxon rank sum test; $T_{21,26}=605 ; p<$ $0.05)$. Mean action potential frequencies did not differ significantly, presumably because distributions were markedly skewed (see Figs. 1, 4; untreated $=1.6 \pm 0.5 \mathrm{~Hz}, n=26$; dependent $=$ $3.4 \pm 1.1 \mathrm{~Hz}, n=25 ; p>0.1$; unpaired $t$ test). Action potential frequency of the in vitro morphine group in the presence of naloxone was similar to untreated slices (median, $0 \mathrm{~Hz}$; mean, $1.0 \pm 0.6 \mathrm{~Hz} ; n=7)$. These results demonstrate that opioidsensitive PAG neurons exhibit signs of naloxone-precipitated withdrawal that are quantitatively distinct from the acute effects of opioids.

\section{The mechanism of naloxone-induced excitation in dependent PAG neurons differs qualitatively from reversal of acute opioid actions}

If specific adaptations in opioid-sensitive neurons were responsible for the naloxone-induced excitation in slices from dependent animals, then ionic mechanisms other than altered sensitivity of the previously characterized (Chieng and Christie, 1994a; Os-

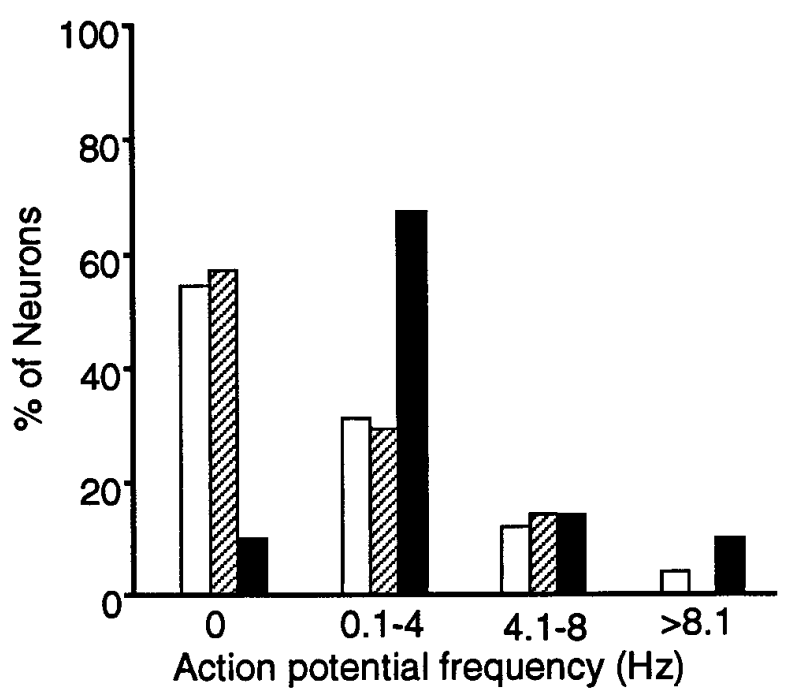

Figure 4. Spontaneous action potential frequencies of opioid-sensitive PAG neurons in the absence of opioids or presence of naloxone. Spontaneous action potential frequencies in the absence of applied currents were sampled in control neurons in the absence of opioids (open bars), control neurons in the presence of morphine ( $5 \mu \mathrm{M}$ for up to $10 \mathrm{hr}$ ) plus naloxone (100 $\mathrm{nM}$ or $1 \mu \mathrm{M}$; hatched bars), or neurons from dependent animals in the presence of morphine plus naloxone (filled bars). Opioid-sensitive neurons from dependent animals displayed a greater proportion and frequency of action potential activity than those in control groups.

borne et al., 1996) opioid-induced K conductance might be involved. Such mechanisms, if they exist, could be evident as a deviation of the equilibrium potential of the conductance from that predicted by the Nernst equation for a K conductance $\left(E_{\mathrm{K}}\right)$. Indeed, analyses of voltage-current relationships of naloxoneinduced depolarizations in slices from dependent animals indicated that they did not reverse polarity near the expected $E_{\mathrm{K}}(\mathrm{Fig}$. $5 A$ ). Reversals within a range less than $-130 \mathrm{mV}$ were obtained in only 3 of 14 neurons tested $(-108 \pm 8 \mathrm{mV})$. In others (Fig. $5 A$ ), reversal potentials were estimated by extrapolation of voltagecurrent relationships $(-154 \pm 10 \mathrm{mV} ; n=10)$. Similar results were observed with voltage clamp (Fig. $5 B$ ). The reversal potential pooled from these conditions was $-143 \pm 9 \mathrm{mV}(n=14)$. In contrast, opioid agonist-induced currents reversed polarity near the expected $E_{\mathrm{K}}$ in slices from untreated rats $(-111 \pm 3 \mathrm{mV} ; n=$ 20; $p<0.001$; unpaired $t=3.9$; df $=32$ ). Naloxone-induced currents also reversed polarity near the expected $E_{\mathrm{K}}$ in the untreated plus in vitro morphine group $(-113 \pm 3 \mathrm{mV} ; n=7 ; p<$ 0.05 ; unpaired $t=2.3$; df $=19$ ). Figure $5 C$ shows subtracted current-voltage relationships of PAG neurons from dependent (naloxone-morphine) and untreated (opioid-control) groups (directly from voltage-clamp data and calculated from applied currents in $5 \mathrm{mV}$ increments from current-clamp data). In neurons from dependent animals that were not depolarized by naloxone at potentials between -60 and $-80 \mathrm{mV}$, no effects on currentvoltage relationships were detected over the entire range from $-60 \mathrm{mV}$ to $-130 \mathrm{mV}$ (data not shown). These results demonstrate that the naloxone-induced depolarization in opioidsensitive neurons from dependent animals involves a mechanism other than simple antagonism of a $\mathrm{K}$ current induced by the presence of morphine.

A possible explanation of nonreversal of the depolarization at the predicted $E_{\mathrm{K}}$ is that chronic morphine treatment induced a novel opioid-sensitive current distinct from the inwardly rectifying 


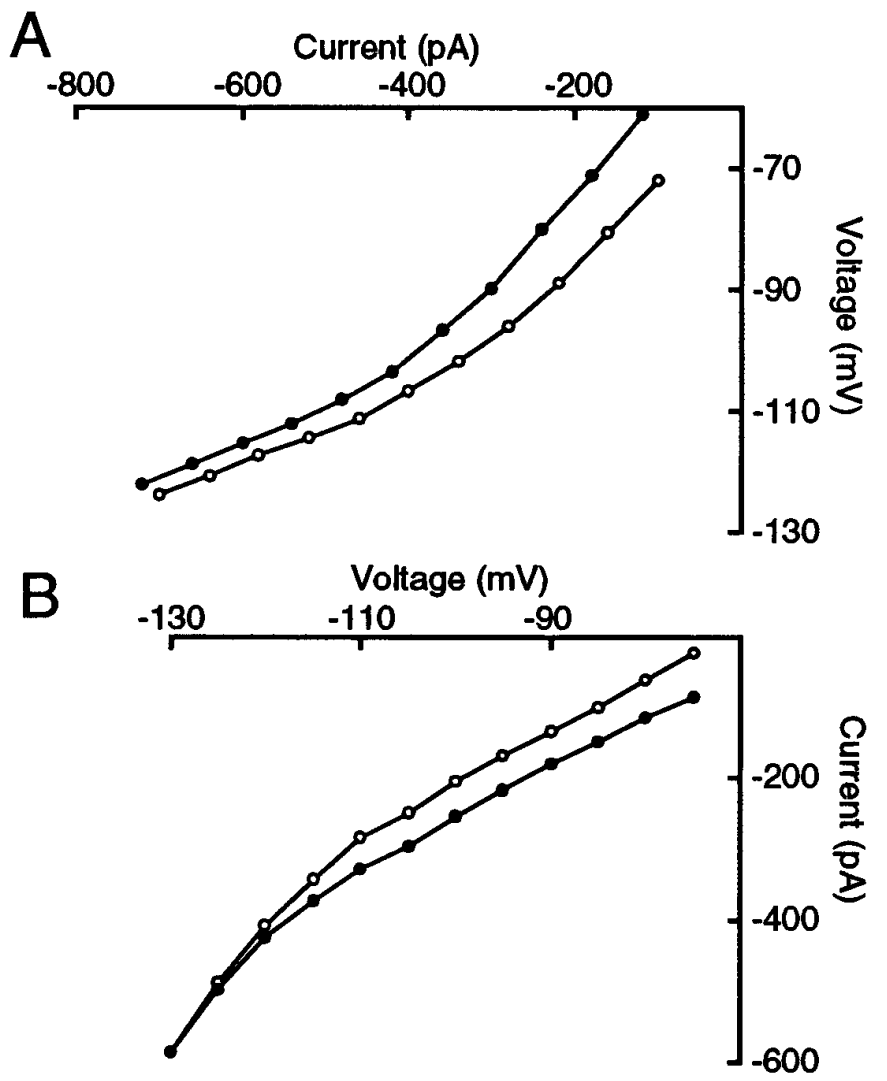

C

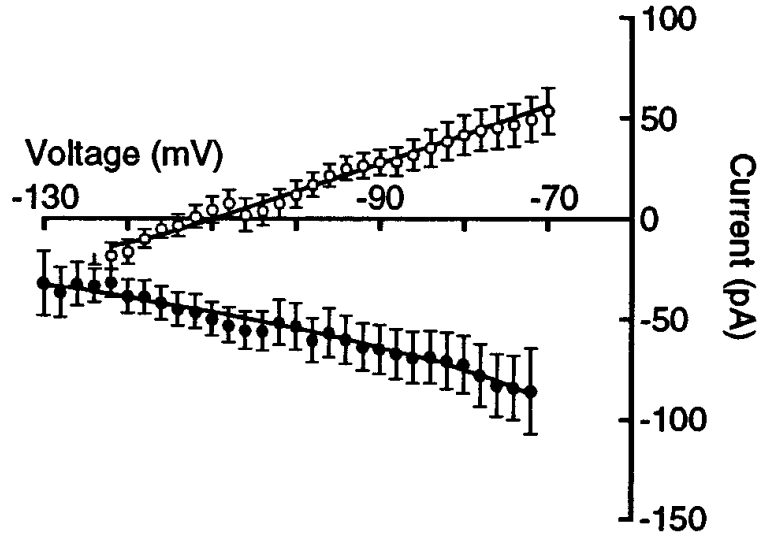

Figure 5. Naloxone-induced depolarizations did not reverse polarity near expected $E_{\mathrm{K}}$ in neurons from dependent animals. $A$, The voltage-current relationship of a neuron from a dependent animal in the presence of morphine (5 $\mu \mathrm{M}$; open circles) and in the presence of morphine plus naloxone $(1 \mu \mathrm{M}$; filled circles $)$. The depolarization did not reverse polarity or converge in the range positive of $-125 \mathrm{mV}$. B, A current-voltage relationship (voltage clamp) of the naloxone-induced inward current from another neuron from a dependent animal in the presence of morphine (5 $\mu \mathrm{M}$; open circles $)$ and in the presence of morphine plus naloxone $(1 \mu \mathrm{M}$; filled circles). $C$, Pooled current-voltage relationships (calculated as described in Results) of the naloxone-induced depolarization in 14 neurons from dependent animals ( filled circles; control in the presence of morphine was subtracted) and for the met-enkephalin-induced hyperpolarization in control slices ( $n=15$; control in the absence of opioids was subtracted).

$\mathrm{K}$ current present in untreated PAG neurons. We therefore attempted to block the agonist-induced $\mathrm{K}$ current to resolve any other opioid-sensitive current present. In the presence of $\mathrm{BaCl}_{2}$ $(10 \mathrm{~mm})$ plus tetrodotoxin $(1 \mu \mathrm{M})$ to block agonist-induced $\mathrm{K}$ currents (Chieng and Christie, 1995c), naloxone-induced depolarizations were still observed ( $\pm 0.3 \mathrm{mV}$ from $-80 \mathrm{mV} ; n=3$ ), and a clear reversal or convergence of current-voltage relationships over the range -60 to $-130 \mathrm{mV}$ was not observed. The ionic nature of the novel opioid-induced current therefore remains unclear.

\section{The naloxone-induced current was not inhibited by blockers of synaptic transmission}

The novel current observed in the presence of naloxone could be attributable either to intrinsic adaptations that develop in opioidsensitive PAG neurons or adaptations to synaptic transmission impinging more or less specifically on opioid-sensitive PAG neurons. Tetrodotoxin $(1 \mu \mathrm{M} ; n=6)$ affected neither the amplitude (Fig. 6) nor the slope of voltage-current relationships (data not shown) induced by naloxone in neurons from dependent slices, ruling out the possibility that the novel current was attributable to transmitters released as a result of excitation of interneurons within slices from dependent animals.

We reported previously that $\mu$-opioids inhibit both glutamatergic and GABAergic components of electrically evoked synaptic potentials in PAG neurons (Chieng and Christie, 1994b), raising the possibility that the novel naloxone-induced current was attributable to action potential-independent release of one or both of these transmitters. However, superfusion of CNQX $(10 \mu \mathrm{M} ; n=$ $3)$ with APV $(50 \mu \mathrm{M})$ or bicuculline $(30 \mu \mathrm{M} ; n=4)$ did not inhibit naloxone-induced depolarizations (Fig. 6). The reversal potentials of naloxone-induced depolarizations also failed to converge toward $E_{\mathrm{K}}$ in the presence of these blockers (Fig. $6 B, C$ ).

Increased activity of catecholamine-containing neurons located in the locus coeruleus (Aghajanian, 1978) and ventral medulla (Stornetta et al., 1993) have been implicated in opioid withdrawal. We reported previously that $\alpha_{1}$-adrenoceptor agonists produce an inward current in PAG neurons, which does not reverse polarity at $E_{\mathrm{K}}$ (Vaughan et al., 1996), raising the possibility that the novel naloxone-induced current was attributable to withdrawal-induced catecholamine release from terminals in PAG, thereby activating $\alpha_{1}$-adrenoceptors on opioid-sensitive neurons. However, prazosin (300 nM; $n=3$ ) affected neither naloxone-induced depolarizations (Fig. 6A) nor the slope of voltage-current relationships (data not shown).

Naloxone-induced withdrawal depolarization of opioidsensitive PAG neurons was surmounted by other agents that open $\mathrm{K}$ channels

We reported previously that $\alpha_{2}$-adrenoceptor (Vaughan et al., 1996) and $\mathrm{GABA}_{\mathrm{B}}$-receptor (Chieng and Christie, 1995c) agonists increase an inwardly rectifying $\mathrm{K}$ conductance in $\mathrm{PAG}$ neurons. Naloxone-induced depolarizations were overcome by both clonidine (1 $\mu \mathrm{M} ; n=5)$ and baclofen (30 $\mu \mathrm{M} ; n=6$; Fig. $7 A)$. Hyperpolarizations induced by clonidine and baclofen in the presence of naloxone reversed polarity near expected $E_{\mathrm{K}}(-123$ $\pm 4 \mathrm{mV}, n=5$ for clonidine; $-115 \pm 3 \mathrm{mV}, n=5$ for baclofen; Fig. $7 B, C)$.

\section{Location of naloxone-induced withdrawal depolarization of opioid-sensitive PAG neurons}

Locations of opioid-sensitive and opioid-insensitive PAG neurons recorded from opioid-dependent slices are plotted in Figure 8. Neurons from untreated and in vitro morphine groups were from similar locations (data not shown). There did not seem to be a discrete localization of opioid-sensitive neurons that were depolarized by naloxone in the ventrolateral PAG, nor were there any 


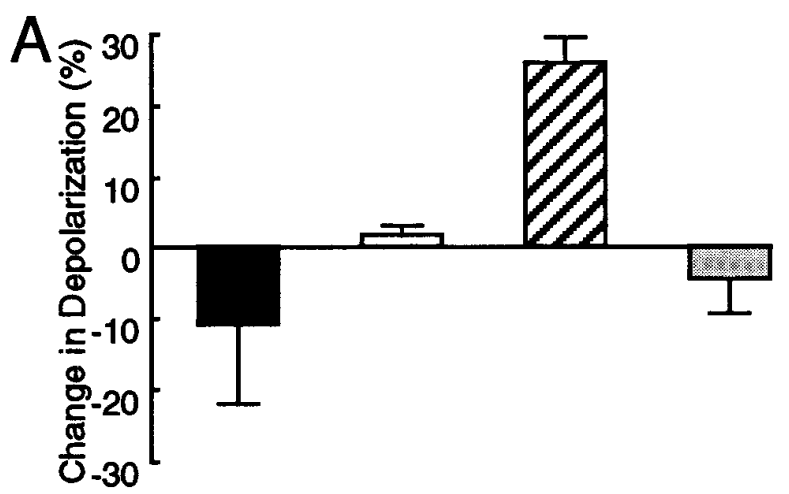

B
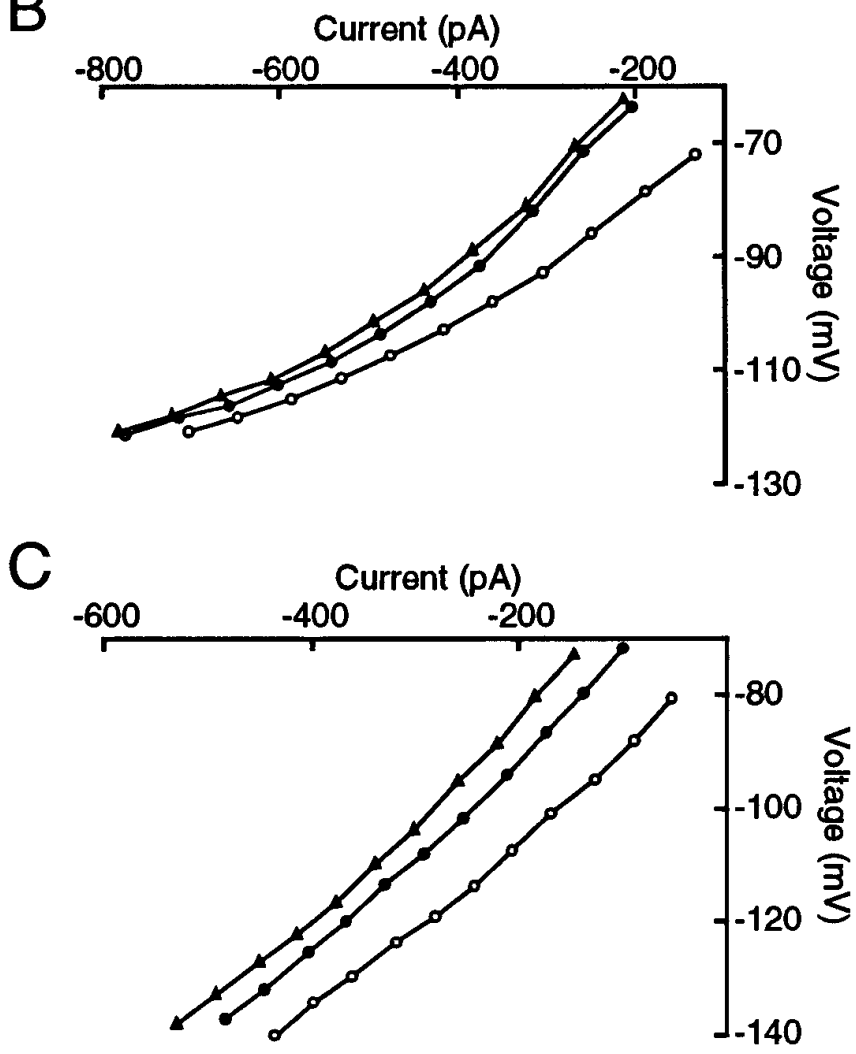

Figure 6. Blockers of synaptic neurotransmission did not inhibit naloxoneinduced depolarization in neurons from dependent animals. $A$, The change in amplitude of the naloxone-induced depolarization in neurons from dependent animals in the presence of tetrodotoxin ( $1 \mu \mathrm{M} ; n=3$; filled bar $)$, CNQX $(10 \mu \mathrm{M})$ plus APV $(50 \mu \mathrm{M} ; n=3$; open bar $)$, bicuculline $(30 \mu \mathrm{M} ; n=4$; hatched bar), and prazosin (300 nM; $n=3$; shaded bar). Action potential activity was prevented throughout these experiments by application of constant current. $B$, An example of a voltage-current relationship of a neuron from a dependent animal in the presence of morphine (5 $\mu \mathrm{M}$; open circles $)$, in the presence of morphine plus naloxone ( $1 \mu \mathrm{M}$; filled circles), and during additional superfusion of CNQX plus APV (filled triangles). $C$, An example of a voltage-current relationship of another neuron from a dependent animal in the presence of morphine ( $5 \mu \mathrm{M}$; open circles $)$, in the presence of morphine plus naloxone $(1 \mu \mathrm{M}$; filled circles $)$, and during additional superfusion of bicuculline (filled triangles).

differences in diameters (depolarized by naloxone, $25 \pm 1 \mu \mathrm{m}$, $n=23$ vs not depolarized, $22 \pm 1 \mu \mathrm{m}, n=26$ ) or morphology.

\section{DISCUSSION}

The present study has demonstrated that chronic treatment with morphine induces both tolerance and dependence in single, opioid-sensitive ventrolateral PAG neurons. Tolerance to morphine conceivably could arise from two types of adaptive mechanism. Functional uncoupling of opioid receptors from their effectors after chronic morphine treatment has been widely reported (Law et al., 1982; Chavkin and Goldstein, 1984; Christie et al., 1987; Puttfarcken et al., 1988). Alternatively, or perhaps additionally, adaptive changes in the basal excitability of opioid-sensitive neurons that overcome the inhibitory effects of morphine could also explain functional tolerance (Fry et al., 1980). It is not yet clear which explanation accounts for tolerance in the present studies, but the observed naloxone-induced excitation exceeding normal baseline suggests that the latter mechanism might be partly responsible.

The withdrawal-induced increase in action potential activity differed quantitatively from simple reversal of acute actions of opioids in opioid-sensitive ventrolateral PAG neurons, suggesting the development of dependence. Several lines of evidence suggest that this was attributable to adaptations resulting specifically from chronic treatment with morphine. First, the effect of naloxone in neurons from dependent animals was not attributable to shortterm adaptations arising from presence of morphine for several hours in vitro, because action potential activity of neurons from the in vitro morphine group (in the presence of naloxone) was very similar to that of untreated control slices. Second, the excitation was confined primarily to opioid-sensitive PAG neurons, suggesting that it involved adaptations within opioid-sensitive neurons or in local neural networks that interact more or less specifically with opioid-sensitive neurons. Third, the depolarization was sustained for the duration of superfusion with naloxone, suggesting it did not result from a transient rebound phenomenon. Finally, the excitation resulted from occupation of opioid receptors, because the inactive enantiomer (+)-naloxone had no effect on neurons that subsequently were depolarized by $(-)$-naloxone. Furthermore, high concentrations of the selective $\mu$-receptor agonist DAMGO surmounted the naloxone-induced excitation.

In addition to the quantitative withdrawal-induced excitation of PAG neurons from dependent animals, the mechanism of excitation differed qualitatively from reversal of the acute actions of morphine in this tissue, strongly suggesting that adaptations of the membrane properties of these neurons were responsible for the withdrawal-induced excitation. In contrast to untreated slices (see also Chieng and Christie, 1994a; Osborne et al., 1996), naloxoneinduced depolarizations in slices from dependent animals reversed polarity at potentials substantially more negative than expected $E_{\mathrm{K}}$. We attempted to isolate the current responsible for this shift in reversal potential by blocking the opioid-induced $\mathrm{K}$ conductance with high extracellular concentrations of Ba (Chieng and Christie, 1995c), but this procedure did not produce obvious convergence of voltage-current relationships toward a new reversal potential.

Adaptations underlying increased action potential activity and apparent changes in the ionic basis of opioid actions in PAG neurons undergoing withdrawal conceivably could be attributable either to adaptations that develop within opioid-sensitive neurons or, alternatively, in local neural networks that interact more or less specifically with opioid-sensitive neurons. The lack of effect of tetrodotoxin ruled out an involvement of neurotransmitters released as a consequence of increased action potential activity of neurons within slices. We demonstrated previously that both GABAergic and glutamatergic transmission in PAG are inhibited acutely by $\mu$-opioid receptor agonists (Chieng and Christie, 1994b). A withdrawal-induced increase in action potential- 


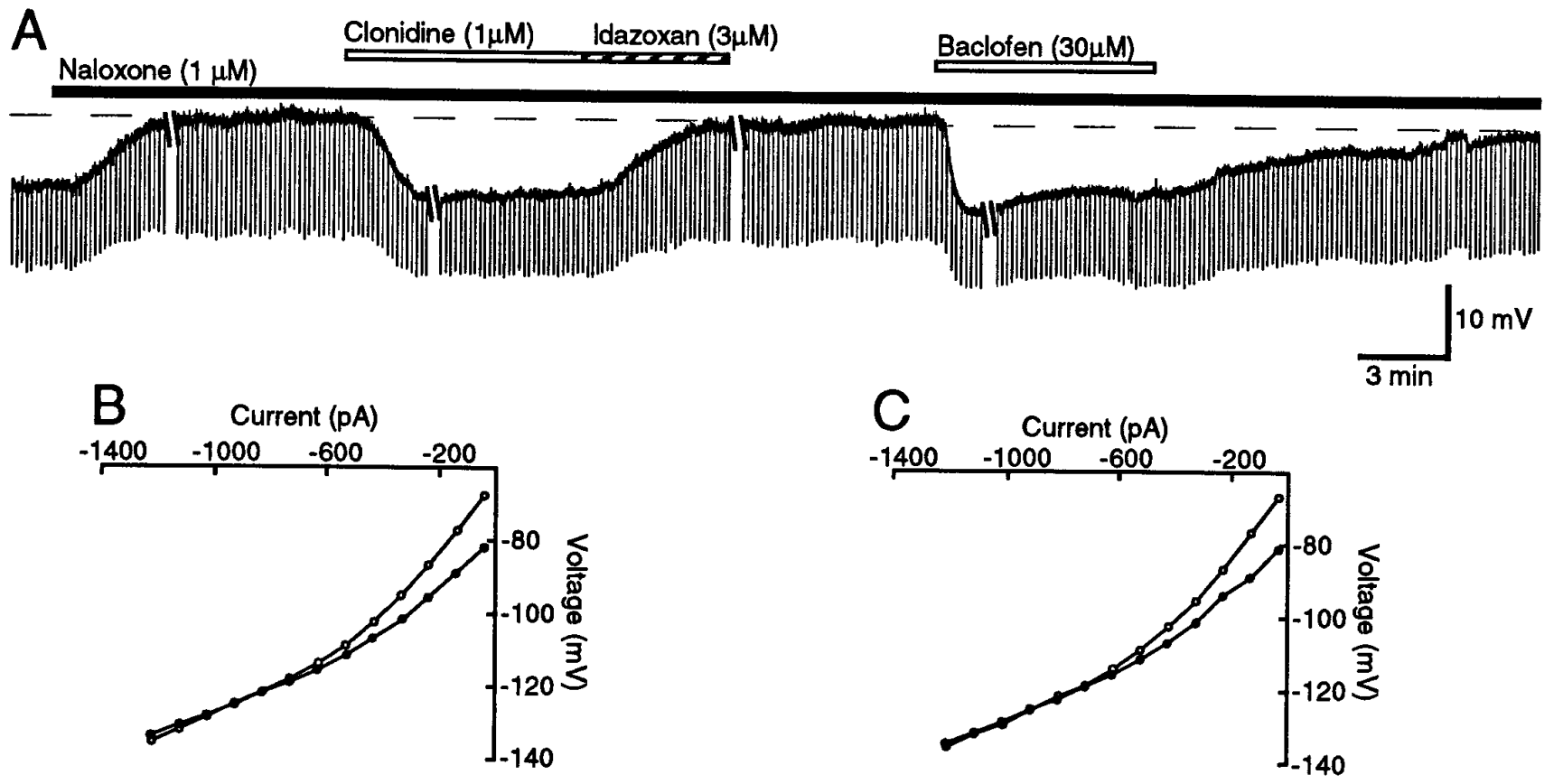

Figure 7. Clonidine and baclofen reversed naloxone-induced depolarizations in neurons from dependent animals. $A$, The naloxone-induced depolarization in the presence of morphine $(5 \mu \mathrm{M})$ in a single neuron from an opioid-dependent animal (initial membrane potential, $-86 \mathrm{mV},-170 \mathrm{pA} ;-200$ $\mathrm{pA}, 300 \mathrm{msec}$ constant current pulses applied throughout). Superfusion of clonidine $(1 \mu \mathrm{M})$ reversed the naloxone-induced depolarization, and this effect was antagonized by the $\alpha_{2}$-adrenoceptor antagonist idazoxan $(3 \mu \mathrm{M})$, thereby restoring the naloxone-induced depolarization. Baclofen ( $\left.30 \mu \mathrm{M}\right)$ then reversed the naloxone-induced depolarization in the same neuron. Voltage-current relationships were determined during breaks shown in the traces (duration of each break was $\sim 2 \mathrm{~min}$ ). $B$, The voltage-current relationship of the same neuron in the presence of naloxone (open circles) and in the presence of naloxone plus clonidine (filled circles). $C$, The voltage-current relationship of the same neuron in the presence of naloxone (open circles) and in the presence of naloxone plus baclofen (filled circles).

independent release of GABA or glutamate would be expected to depolarize neurons and shift the reversal potential in the direction observed in the present study. However, superfusion of bicuculline and CNQX neither inhibited naloxone-induced depolarizations, nor did they restore convergence of voltage-current relationships. The small, nonconvergent increase in the naloxoneinduced depolarization observed in the presence of bicuculline might suggest that the mechanism responsible for the naloxoneinduced depolarization is inhibited by tonically released GABA.

We have reported previously that noradrenaline acting on $\alpha_{1}$ adrenoceptors depolarizes PAG neurons and that the conductance involved does not reverse polarity near $E_{\mathrm{K}}$ (Vaughan et al., 1996). The PAG is densely innervated by catecholaminecontaining terminals (Herbert and Saper, 1992), and increased probability of transmitter release from peripheral noradrenergic nerve terminals has been reported during opioid withdrawal (Lavidis, 1995). Increased release of catecholamines during withdrawal could therefore account for the tetrodotoxin-insensitive effects observed in the present study, but the lack of effect of prazosin mitigates against this possibility. However, it remains possible that an as yet unidentified substance is released during naloxone-precipitated withdrawal in a tetrodotoxin-insensitive manner in the vicinity of opioid-sensitive PAG neurons and is responsible for the observed shift in reversal potential.

Postsynaptic mechanisms also could account for the adaptations underlying increased action potential activity and changes in reversal potential of opioid actions in PAG neurons undergoing withdrawal. Ionic mechanisms such as enhancement of either a cation or chloride (because of the use of $\mathrm{KCl}$-filled electrodes; Chieng and Christie, 1994b) conductance would be expected to
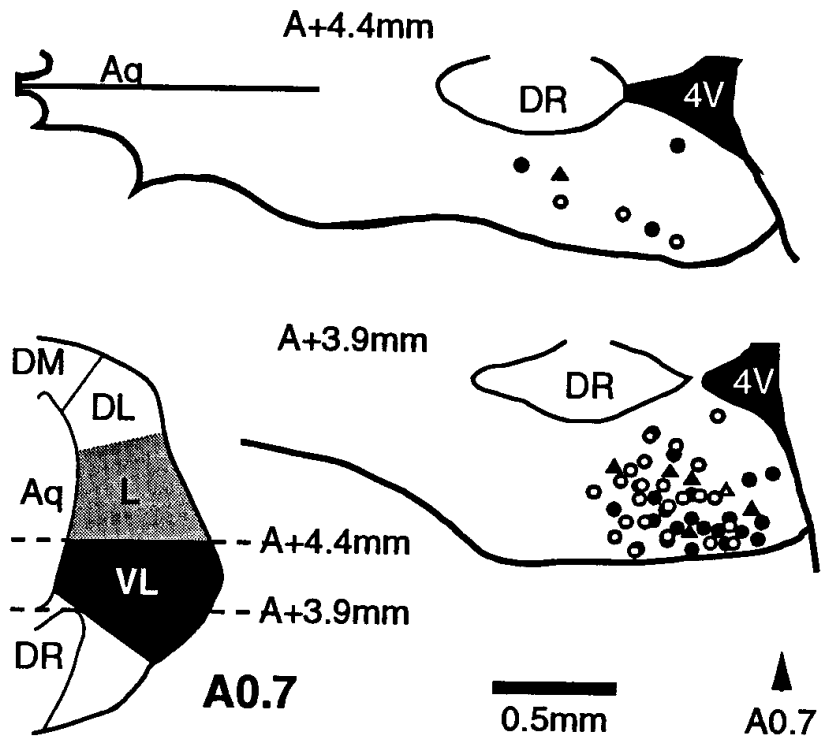

Figure 8. Locations in the ventrolateral PAG of impaled neurons from opioid-dependent animals. The two horizontal sections through the PAG, 3.9 and $4.4 \mathrm{~mm}$ dorsal to the interaural plane, show locations of opioid-sensitive neurons depolarized by naloxone (filled circles), opioid-insensitive neurons depolarized by naloxone (filled triangles), opioid-insensitive neurons unaffected by naloxone (open circles), and an opioid-sensitive neuron that was unaffected by naloxone (open triangle). Inset shows a coronal section of PAG $0.7 \mathrm{~mm}$ rostral to the interaural plane, indicating the levels of horizontal sections (arrow). $4 \mathrm{~V}$, Fourth ventricle; $A q$, aqueduct; $D L$, dorsolateral PAG; $D M$, dorsomedial PAG; $D R$, dorsal raphe; $L$, lateral PAG; $V L$, ventrolateral PAG. 
sum with antagonism of the opioid-induced $\mathrm{K}$ conductance by naloxone to produce an inward current that reverses polarity more negative than $E_{\mathrm{K}}$, as has been proposed to occur during withdrawal as a result of hypertrophy of the adenylyl cyclase cascade in the locus coeruleus (Nestler et al., 1993) (cf. Christie et al., 1987; Travagli et al., 1995). However, no evidence was found for opioid-induced conductances, other than an increased K conductance, in PAG neurons from untreated animals (Chieng and Christie, 1994a; Osborne et al., 1996). This implies that adaptations to the adenylyl cyclase cascade or other second messenger systems (Mayer et al., 1995), if they do induce non-K conductances in PAG neurons, do so exclusively after chronic treatment with opioids. Supporting the possible involvement of protein kinases, the serine-threonine kinase inhibitor $\mathrm{H} 7$ profoundly inhibited naloxone precipitated withdrawal behavior when microinjected into the PAG (Maldonado et al., 1995).

The very negative reversal potential of naloxone-induced currents also could be attributable to spatial redistribution of opioid actions within PAG neurons after chronic morphine treatment, i.e., a significant proportion of $\mathrm{K}$ channels could be coupled to $\mu$-receptors at electrically remote sites and therefore beyond the range of adequate experimental control of membrane potential (see Travagli et al., 1995; Fiorillo and Williams, 1996). However, superfusion of $\mathrm{Ba}$, which should block agonist-induced K currents, did not prevent naloxone-induced depolarizations.

Suppression of withdrawal-induced excitation of PAG neurons by clonidine is consistent with the role of $\alpha_{2}$-adrenoceptor agonists in inhibition of opioid withdrawal behavior (Aghajanian, 1978). The $\mathrm{GABA}_{\mathrm{B}}$ receptor agonist baclofen had similar effects and has been reported to alleviate some signs of opioid withdrawal in humans (Krystal et al., 1992). Hyperpolarizations produced by clonidine and baclofen in the presence of naloxone reversed polarity at values close to expected $E_{\mathrm{K}}$, although there was a tendency for the clonidine reversal potential to be more negative. This suggests that adaptations of opioid receptorcoupling to effectors, which give rise to very negative reversal potentials, were not shared by $\alpha_{2}$ - and $\mathrm{GABA}_{\mathrm{B}}$-receptors.

The present demonstration of naloxone-precipitated withdrawal in single opioid-sensitive neurons within the ventrolateral PAG is consistent with previous functional studies suggesting the involvement of the region in expression of withdrawal signs (Bozarth and Wise, 1984; Maldonado et al., 1992; Bozarth, 1994), as well as with biochemical indices of increased neural activity in the ventrolateral PAG (Kimes and London, 1989; Stornetta et al., 1993; Chieng et al., 1995; Couceyro and Douglass, 1995) during withdrawal. The PAG is organized into anatomically and functionally distinct neural columns that extend along the rostrocaudal axis and mediate distinct physiological functions (Bandler and Shipley, 1994), some of which are generally consistent with withdrawal behavior. Direct stimulation of the ventrolateral PAG in opioid-naive animals with excitatory amino acids produces quiescence, hyporeactivity, hypotension, bradycardia, and opioidmediated analgesia (Bandler and Shipley, 1994). These functions are qualitatively opposite to many signs of opioid withdrawal evoked by direct injections of opioid antagonists or chronic infusion of opioid agonists into the PAG (Bozarth and Wise, 1984; Maldonado et al., 1992; Bozarth, 1994). Although this seems contradictory, it is unlikely that the population of neurons stimulated by excitants (presumably output neurons) is the same as the opioid-sensitive neurons excited during opioid withdrawal. Opioids have been proposed to act directly on GABAergic interneurons in the PAG, thereby disinhibiting neurons that project to the ventral medulla (Basbaum and Fields, 1984; Reichling et al., 1988). Indeed, very few ventrolateral PAG neurons that project to the ventral medulla are directly sensitive to opioids (Osborne et al., 1996).

The precise functional role of opioid-sensitive neurons that undergo naloxone-precipitated withdrawal in the ventrolateral PAG remains unclear. It is possible that they represent a subpopulation of opioid-sensitive GABAergic interneurons, but this has yet to be confirmed. Neurons within the ventrolateral PAG project to many brain regions (Bandler and Shipley, 1994; Cameron et al., 1995), some of which are thought to be involved in expression of signs of opioid withdrawal (Maldonado et al., 1992), e.g., the nucleus accumbens, hypothalamus, and amygdala. Intrinsic naloxone-precipitated withdrawal in opioid-sensitive neurons within the ventrolateral PAG could therefore participate in the expression of withdrawal behavior mediated by a number of brain regions.

\section{REFERENCES}

Aghajanian GK (1978) Tolerance of locus coeruleus neurones to morphine and suppression of withdrawal response by clonidine. Nature 276:186-188.

Akaoka H, Aston-Jones G (1991) Opiate withdrawal-induced hyperactivity of locus coeruleus neurons is substantially mediated by augmented excitatory amino acid input. J Neurosci 11:3830-3839.

Andrade R, Vandermaelen CP, Aghajanian GK (1983) Morphine tolerance and dependence in the locus coeruleus: single cell studies in brain slices. Eur J Pharmacol 91:161-169.

Bandler R, Shipley MT (1994) Columnar organization in the midbrain periaqueductal gray: modules for emotional expression? Trends Neurosci 17:379-389.

Basbaum AI, Fields HL (1984) Endogenous pain control systems: brainstem spinal pathways and endorphin circuitry. Annu Rev Neurosci 7:309-338.

Bozarth MA (1994) Physical dependence produced by central morphine infusions: an anatomical mapping study. Neurosci Biobehav Rev 18:373-383.

Bozarth MA, Wise RA (1984) Anatomically distinct opiate receptor fields mediate reward and physical dependence. Science 224:516-517.

Cameron AA, Khan IA, Westlund KN, Willis WD (1995) The efferent projections of the periaqueductal gray in the rat: a Phaseolus vulgarisleukoagglutinin study. II. Descending projections. J Comp Neurol 351:585-601.

Chavkin C, Goldstein A (1984) Opioid receptor reserve in normal and morphine-tolerant guinea pig ileum myenteric plexus. Proc Natl Acad Sci USA 81:7253-7257.

Chieng B, Christie MJ (1994a) Hyperpolarization by opioids acting on $\mu$-receptors of a subpopulation of rat periaqueductal gray neurones in vitro. Br J Pharmacol 113:121-128.

Chieng B, Christie MJ (1994b) Inhibition by opioids acting on $\mu$-receptors of GABAergic and glutamatergic postsynaptic potentials in single rat periaqueductal gray neurones in vitro. $\mathrm{Br} \mathrm{J}$ Pharmacol 113:303-309.

Chieng B, Christie MJ (1995a) Opioid withdrawal in single opioidsensitive neurons of rat periaqueductal gray. Soc Neurosci Abstr 21:723P.

Chieng B, Christie MJ (1995b) Lesions to terminals of noradrenergic locus coeruleus neurones do not inhibit opiate withdrawal behaviour in rats. Neurosci Lett 186:37-40.

Chieng B, Christie MJ (1995c) Hyperpolarization by $\mathrm{GABA}_{\mathrm{B}}$ receptor agonists in midbrain periaqueductal gray neurones in vitro. $\mathrm{Br} \mathrm{J}$ Pharmacol 116:1583-1588.

Chieng B, Keay KA, Christie MJ (1995) Increased fos-like immunoreactivity in the periaqueductal gray of anaesthetised rats during opiate withdrawal. Neurosci Lett 183:79-82.

Christie MJ, Williams JT, North RA (1987) Cellular mechanisms of opiate tolerance: studies in single brain neurones. Mol Pharmacol 32:633-638.

Collier HOJ, Francis DL, Schneider C (1972) Modification of morphine withdrawal by drugs interacting with humoral mechanisms: some contradictions and their interpretation. Nature 237:220-223. 
Couceyro P, Douglass J (1995) Precipitated morphine withdrawal stimulates multiple activator protein-1 signaling pathways in rat brain. Mol Pharmacol 47:29-39.

Fiorillo CD, Williams JT (1996) Opioid desensitization: interactions with G-protein-coupled receptors in the locus coeruleus. J Neurosci 16:1479-1485.

Fry JP, Herz A, Zieglgansberger W (1980) A demonstration of naloxoneprecipitated opiate withdrawal on single neurons in the tolerant/dependent rat brain. Br J Pharmacol 68:585-592.

Herbert H, Saper CB (1992) Organization of medullary adrenergic and noradrenergic projections to the periaqueductal gray matter in the rat. J Comp Neurol 315:34-52.

Johnson SM, Duggan AW (1981) Tolerance and dependence of dorsal horn neurones of the cat: the role of the opiate receptors of the substantia gelatinosa. Neuropharmacology 20:1033-1038.

Kennedy C, Henderson G (1991) $\mu$-Opioid receptor inhibition of calcium current: development of homologous tolerance in single SH-SY5Y cells after chronic exposure to morphine in vitro. Mol Pharmacol 40:1000-1005.

Kennedy C, Henderson G (1992) Chronic exposure to morphine does not induce dependence at the level of the calcium current in human SH-SY5Y cells. Neuroscience 49:937-944.

Kimes AS, London ED (1989) Glucose utilization in the rat brain during chronic morphine treatment and naloxone-precipitated withdrawal. J Pharmacol Exp Ther 248:538-545.

Kogan J, Nestler E, Aghajanian G (1992) Elevated basal firing rates and enhanced responses to 8-Br-cAMP in locus coeruleus neurons in brain slices from opiate-dependent rats. Eur J Pharmacol 211:47-53.

Krystal JH, McDougle CJ, Kosten TR, Price LH, Aghajanian GK, Charney DS (1992) Baclofen-assisted detoxification from opiates. A pilot study. J Subst Abuse Treat 9:139-142.

Lavidis NA (1995) Effect of chronic morphine treatment on transmitter release from sympathetic varicosities of the mouse vas deferens. $\mathrm{Br} \mathbf{J}$ Pharmacol 116:2860-2865.

Law PY, Hom DS, Loh HH (1982) Loss of opiate receptor activity in neuroblastoma $\times$ glioma NG108-15 hybrid cells after chronic opiate treatment: a multiple step process. Mol Pharmacol 22:1-4.

Maldonado R, Stinus L, Gold LH, Koob GF (1992) Role of different brain structures in the expression of the physical morphine withdrawal syndrome. J Pharmacol Exp Ther 261:669-677.

Maldonado R, Valverde O, Garbay C, Roques BP (1995) Protein kinases in the locus coeruleus and periaqueductal gray matter are involved in the expression of opiate withdrawal. Naunyn Schmiedebergs Arch Pharmacol 352:565-575.

Mayer DJ, Mao J, Price DD (1995) The development of morphine tolerance and dependence is associated with translocation of protein kinase C. Pain 61:365-374.

Nestler EJ, Hope BT, Widnell KL (1993) Drug addiction: a model for the molecular basis of neural plasticity. Neuron 11:995-1006.

Osborne PB, WIlliams JT (1995) Characterization of acute homologous desensitization of $\mu$-opioid receptor-induced currents in locus coeruleus neurons. Br J Pharmacol 115:925-932.

Osborne PB, Vaughan CW, Wilson HI, Christie MJ (1996) Opioid inhibition of rat periaqueductal gray neurones with identified projections to the rostral ventromedial medulla in vitro. J Physiol (Lond) 490:383-389.

Paxinos G, Watson C (1986) The rat brain in stereotaxic coordinates, 2nd Ed. Sydney, Australia: Academic.

Puttfarcken PS, Werling LL, Cox BM (1988) Effects of chronic morphine exposure on opioid inhibition of adenylyl cyclase in $7315 \mathrm{c}$ cell membranes: a useful model for the study of tolerance at $\mu$-opioid receptors. Mol Pharmacol 33:520-527.

Reichling DB, Kwiat GC, Basbaum AI (1988) Anatomy, physiology, and pharmacology of the periaqueductal gray contribution to antinociceptive controls. Prog Brain Res 77:31-46.

Russell JA, Leng G, Bicknell RJ (1995) Opioid tolerance and dependence in the magnocellular oxytocin system: a physiological mechanism? Exp Physiol 80:307-340.

Sharma SK, Klee WA, Nirenberg M (1975) Dual regulation of adenylate cyclase accounts for narcotic dependence and tolerance. Proc Natl Acad Sci USA 72:3092-3096.

Stornetta RL, Norton FE, Guyenet PG (1993) Autonomic areas of rat brain exhibit increased fos-like immunoreactivity during opiate withdrawal in rats. Brain Res 624:19-28.

Travagli RA, Dunwiddie TV, Williams JT (1995) Opioid inhibition in locus coeruleus. J Neurophysiol 74:519-528.

Tung CS, Grenhoff J, Svensson TH (1990) Morphine withdrawal responses of rat locus coeruleus neurons are blocked by an excitatory amino-acid antagonist. Acta Physiol Scand 138:581-582.

Vaughan CW, Bandler R, Christie MJ (1996) Actions of noradrenaline on rat periaqueductal gray neurones in vitro. J Physiol (Lond) 490:373-381.

Wimpey TL, Opheim KE, Chavkin C (1989) Effects of chronic morphine administration on the mu and delta opioid responses in the CA1 region of the rat hippocampus. J Pharmacol Exp Ther 251:405-411. 